\title{
Feminino e mística: ressonâncias trágicas e barrocas do que ultrapassa o fio das palavras
}

\author{
Feminine and mysticism: tragic and baroque resonances of \\ what goes beyond the thread of words
}

DENISE MAURANO (ida

BRUno Albuquerque (ib

\section{Resumo}

Em seu projeto de retornar à leitura dos textos de Sigmund Freud, de modo a extrair consequências para a clínica e a teoria psicanalítica, Jacques Lacan investigou diversos temas da história do pensamento humano à luz da dinâmica inconsciente. No seu ensino, a dimensão do feminino ocupa um lugar muito particular, que ele articula à experiência mística. O presente artigo destaca alguns pontos centrais deste percurso, traçando aproximações com a tragédia e o barroco. Desse modo, procura mostrar como a psicanálise de orientação lacaniana concebe o feminino não apenas enquanto uma posição na partilha dos sexos, mas também enquanto um lugar mais além da divisão sexual. Em seguida, explora de que maneira essa dimensão que aponta para um gozo Outro, que não o fálico, encontra-se também atrelada ao avanço do tratamento analítico e, em última instância, ao fim de análise. Por fim, investiga de que modo esse processo conecta a perda do asseguramento fálico a uma certa dimensão de dessubjetivação. Esta possibilita um alargamento daqueles enquadramentos que, por meio da operação simbólica denominada complexo de Édipo, delimitam a fantasia inconsciente. Nesse contexto, tratamos, portanto, de um ponto situado mais além do referencial edípico, que ultrapassa o fio das palavras.

Palavras-chave: Psicanálise. Feminino. Mística. Tragédia. Barroco.

\footnotetext{
a Universidade Federal do Estado do Rio de Janeiro (UNIRIO), Rio de Janeiro, RJ, Brasil. Doutora em Filosofia, e-mail: dmaurano@corpofreudiano.com.br

b Universidade Federal de Juiz de Fora (UFJF), Juiz de Fora, MG, Brasil. Mestre em Psicanálise, e-mail: brunopintodealbuquerque@gmail.com
} 


\section{Abstract}

In his project of returning to the reading of Sigmund Freud's texts, in order to extract consequences for the psychoanalytic clinic and theory, Jacques Lacan investigated several themes in the history of human thought in the light of the unconscious dynamics. In his teaching, the dimension of the feminine occupies a very particular place, which he articulates with the mystical experience. This article highlights some central points of this route, drawing approximations with tragedy and baroque. In this way, it seeks to show how Lacanian-oriented psychoanalysis conceives the female not only as a position in the sharing of the sexes, but also as a place beyond the sexual division. Then, it explores how this dimension that points out to an Other jouissance, which is not the phallic, is also linked to the advancement of the analytical treatment and, ultimately, to the end of analysis. Finally, it investigates how this process connects the loss of phallic assurance to a certain dimension of desubjectivation. This enables an extension of those frameworks that, through the symbolic operation called the Oedipus complex, delimit the unconscious fantasy. In this context, we are dealing, therefore, with a point situated beyond the oedipal framework, which goes beyond the thread of words.

Keywords: Psychoanalysis. Feminine. Mysticism. Tragedy. Baroque.

\section{Introdução}

O presente artigo retoma e desenvolve uma questão sobre a qual temos nos debruçado: a abordagem psicanalítica da experiência mística, tal como proposta por Jacques Lacan (cf. MAURANO; ALBUQUERQUE, 2019). Nosso interesse fundamental nesta investigação consiste em aprofundar de que maneira a psicanálise entende o campo do feminino e da mística em estreita conexão entre si. Particularmente, queremos explorar a contribuição original desse renomado psicanalista francês, que pode interessar também a outras disciplinas e suas respectivas abordagens do feminino e da mística.

Ao longo de seu seminário, Lacan promoveu um rigoroso e criativo retorno à obra de Sigmund Freud. Propondo articulações com as mais diversas áreas que compõem o multifacetado tecido da cultura, extraiu consequências de grande envergadura para a clínica e a teoria psicanalíticas. Nesse percurso, investigou questões cruciais que atravessam a história do pensamento, à luz da dinâmica inconsciente. Esse projeto de releitura, no entanto, não consistia em mera repetição automatizada dos enunciados freudianos, mas em uma 
redescoberta das fontes da experiência analítica, que relança sempre de novo à criatividade e à invenção.

Dentre os vários conceitos e elementos teóricos para os quais ofereceu contribuições originais, Lacan avançou significativamente na enigmática questão sobre como a diferença sexual é percebida no inconsciente. Se, no plano anatômico, a diferença entre masculino e feminino não é difícil de ser verificada, no plano psíquico, evidencia-se uma grande questão, a qual, segundo Freud, só é apreensível por meio de metáforas. Em 1915, em As pulsões e seus destinos (FREUD, 2017b [1915]), ele propõe caracterizar as expressões pulsionais masculina e feminina, respectivamente, como ativa e passiva.

Desse modo, multiplicam-se as tentativas de abordar a questão da diferença entre feminino e masculino em psicanálise. Na sequência, apresentamos algumas ideias relativas à distinção entre epopeia e tragédia, as quais pensamos ser operativas para melhor compreender do que se trata quando o analista se refere ao campo do feminino, antes de trabalharmos com o que estamos desenvolvendo na referida pesquisa conjunta.

\section{O feminino e suas ressonâncias na tragédia e no barroco}

Seguindo o rastro freudiano de explorar os fundamentos que deram origem à civilização ocidental, é possível recorrer a uma dualidade clássica no teatro grego para extrair, da arte antiga, elementos de afinidade ética com a clínica psicanalítica. Esse movimento se encontra também na esteira lacaniana, que fundamenta as bases de uma ética da psicanálise não na tradição filosófica estabelecida na Ética a Nicômaco (ARISTÓTELES, 2018 [349 a.C.]), mas na arte trágica, em que a tragédia Antígona tem um destaque privilegiado (SÓFOCLES, 1990 [441 a.C.]). Abordando a tragédia da princesa tebana, Lacan sublinha:

Antígona é uma tragédia, e a tragédia está presente no primeiro plano de nossa experiência, a dos analistas, como é manifesto nas referências que Freud impelido pela necessidade dos bens oferecidos por seu conteúdo mítico encontrou em Édipo, mas também em outras tragédias (LACAN, 2008a [19591960], p. 290) 
A face oculta do amor: a tragédia à luz da psicanálise (MAURANO, 2001) explora a afinidade estrutural entre a ética trágica e a psicanalítica. Esta última, embora não tenha sido sistematizada por Freud, encontra, em sua obra, largos indícios de orientação, explorados por Lacan, sobretudo, em O seminário, livro 7: a ética da psicanálise (LACAN, 2008a [1959-1960]). A aproximação entre os dois campos acima referidos se configura como uma homologia estrutural, como observa Ingrid Vorsatz (2013), dentre outros autores, sobretudo de orientação lacaniana, que aproximam a tragédia e a psicanálise.

Nesse sentido, para demarcarmos modos antinômicos de orientação psíquica, referimo-nos à distinção entre epopeia e tragédia, duas expressões da arte advindas da Antiguidade ${ }^{1}$. Na epopeia, cujos expoentes paradigmáticos podem ser encontrados na llíada (HOMERO, 2015a [século VIII a.C.]) e na Odisseia (HOMERO, 2015b [século VIII a.C.]), o que se afirma é a construção do herói, indivíduo que se destaca da massa. Trata-se do relato de um ato em que há uma luta desigual do homem contra a morte e o seu próprio destino, em que ele encontrará o triunfo da glória na imortalidade, ainda que simbolicamente. Esta é uma das respostas gregas à dor, à morte e ao sofrimento, na qual se valoriza o olhar, a imagem, a forma e a figura. Nela, o ser humano está em uma relação com os outros na qual não aparece divisão interior: ele está decidido e inteiro naquilo que faz. Tal como Apolo, o deus grego homenageado pelo equilíbrio de suas boas medidas e o vigor de sua luz solar, tal perspectiva acima descrita, em diálogo com o pensamento de Friedrich Nietzsche, poderia ser designada como apolínea (cf. NIETZSCHE, 2000 [1871]).

Na tragédia, por outro lado, tal como se pode ver articulado na Trilogia tebana (SÓFOCLES, 1990), dentre outras, o indivíduo é considerado como a causa de um mal, de modo que deve sofrer até desaparecer. Trata-se da discussão sobre um ato, de uma pergunta a respeito do humano, que sinaliza a dissolução do herói, cuja queda aponta para uma perda da individualidade. No pensamento nietzschiano, essa perspectiva poderia ser designada como dionisíaca. Como apontado por Nietzsche em $O$ nascimento da tragédia

\footnotetext{
${ }^{1}$ Retomamos aqui alguns elementos trabalhados em artigo anterior (MAURANO, 2007). 
(NIETZSCHE, 2000 [1871], p. 31-34; § 10), longe de ser fonte de força, a individuação é via de enfraquecimento, sendo isso o que justifica que a morte do herói, no âmbito do teatro trágico, traga como efeito um modo de purgação que é via de fortalecimento.

Com esses elementos, já se pode vislumbrar uma profunda afinidade entre a clínica psicanalítica e a narrativa trágica. O saber suposto ao herói na epopeia é criticado na tragédia, fazendo com que ela figure, na Grécia clássica, como o espaço por excelência de problematização da condição humana. Nesse cenário, acolhe-se o conflito como via pela qual se pode abordar essa condição, levantando uma questão sobre as possibilidades de encontrar caminhos para o desejo de viver que, ao mesmo tempo, não procure cegar a dimensão trágica da vida. Pode-se, então, advir uma pergunta sobre o que é o humano pergunta à qual a tragédia não responde, mas diante da qual ela descortina, com a tessitura da estética poética, os efeitos de um assombro. Na tragédia Antígona, o coro canta:

Há muitos assombros², mas nenhum / é tão assombroso quanto o homem. / [...] Soube aprender sozinho a usar a fala / e o pensamento mais veloz que o vento / e as leis que disciplinam as cidades, / [...] ocorrem-Ihe recursos para tudo / e nada o surpreende sem amparo; / somente contra a morte clamará / em vão por um socorro, embora saiba / fugir até de males intratáveis (SÓFOCLES, 1990 [441 a.C.], p. 215).

Quando o analista convoca o paciente a falar sobre qualquer coisa que Ihe surgir à cabeça ${ }^{3}$, seus piores horrores também são convocados, abrindo caminho para que sejam exploradas as perspectivas nas quais o sujeito se encontra fixado. Assim como na tragédia grega, que conta com a música e a beleza para conduzir ao enfrentamento dos horrores e sair com vontade de

\footnotetext{
2 Na versão citada, o termo usado é "maravilhas", mas optamos por substitui-lo por "assombros", por indicação de Ingrid Vorsatz (2013, p. 211-213), que, em sua rigorosa pesquisa sobre a peça, considerou o termo mais adequado ao original grego deinon.

${ }^{3}$ Em uma das formulações da regra da associação livre, Freud assim se expressou, apresentando sua teoria em terceira pessoa: "Antes de convidá-los [os doentes] à narrativa detalhada do histórico de sua doença, ele [Freud] reforça a instrução de que eles Ihe contem tudo que Ihes vem à cabeça, mesmo se acharem não ser importante, ou se acharem que aquilo não vem ao caso, ou que não faz sentido. Mas com bastante ênfase exige deles que não excluam nenhum pensamento ou nenhuma ocorrência da comunicação pelo fato de Ihes parecer vergonhoso ou embaraçoso" (FREUD, 2017a [1904/1905], p. 54).
} 
viver a vida em toda a sua potência, a ética da psicanálise também se mune da beleza - que se depreende do manejo do amor de transferência, modo pelo qual a psicanálise conceitua a experiência de vinculação ao analista, fundamental para o funcionamento do trabalho - e da música - a qual podemos sustentar que está presente na musicalidade da fala, tal como convocada pela regra fundamental da psicanalise, para que o sujeito evite se ocupar do sentido (cf. MAURANO, 2015).

Esse cenário da análise constitui um espaço privilegiado em que o sujeito poderá explorar qual é a música que o rege e como ele dança de acordo com ela, para que seja possível, eventualmente, mudar o tom, reconfigurar acordes, acrescentar notas, à medida que o analista, acompanhando o encadeamento melódico das pulsões, interfere na partitura que orienta o som e nos passos que constituem o movimento. Essa alteração na cena é possibilitada pela presença do analista, seu silêncio, corte, palavra ou pontuação, mobilizando reconstruções na constituição psíquica do eu e atravessamentos na tela da fantasia.

Entre as origens da cena trágica na Grécia Antiga e a fundação da clínica psicanalítica na Viena contemporânea, há uma expressão artística que propomos considerar herdeira da tragédia. Em relação à arte clássica, que poderia ser considerada herdeira da epopeia, o barroco marca uma contraposição. Na arte barroca, a cultura encontra uma via de expressão de suas antinomias e da força dos afetos em detrimento da precisão das formas, o que nos remete diretamente à problematização explorada pelo conflito trágico. O barroco evoca ainda uma relação com o gozo que não escoa pelos trilhamentos da satisfação narcísica, do regozijo frente à autoafirmação, da identidade como insígnia fálica. Trata-se, ao contrário, de um gesto de entrega, de autotranscendência, que implica em certa dessubjetivação, ao apontar para algo mais além do universo fálico, para a falta, para a constatação de que nem tudo na vida é quantificável, delimitável, explicável, organizável, dizível.

Podemos afirmar que, enquanto a arte clássica se configura como herdeira do espírito épico, a arte barroca se localiza na linhagem hereditária do espírito trágico. Nesse sentido, tanto a tragédia quanto o barroco se apresentam como orientações artísticas que possuem afinidades com a noção de feminino. Trata-se de construções que tentam elucidar esse campo de difícil 
acesso e a respeito do qual se procura encontrar palavras para nomear aquilo que não é conceituável.

A dualidade entre epopeia e tragédia tem em vista não somente o campo da arte, mas também modos distintos de organização psíquica. Podese pensar, assim, na distinção entre um tipo clássico, que aposta mais na racionalidade e na precisão da linha reta, e um tipo barroco, que aposta mais na complexidade e na diagonalidade da acolhida ao mistério.

Podemos afirmar que tanto Freud quanto Lacan indicam que a abordagem do campo do feminino demanda um passo além daquilo que pode ser abordado pela racionalidade consciente e a capacidade de nomeação. Com efeito, Freud se refere ao feminino como um continente negro (FREUD, 2017C [1926], p. 240), interroga-se sobre o que quer uma mulher e indica que a lógica de orientação fálica não é suficiente para cerni-lo. Lacan inaugura a hipótese de um gozo Outro, creditado ao feminino, suplementar à insuficiência fálica e avizinhado ao gozo místico. Ele chega a lançar o aforismo de que A Mulher, com letra maiúscula, não existe, para marcar a impossibilidade de que uma mulher o seja de forma total e absoluta, dado que não existe aquela que não esteja, em parte, submetida à logica fálica, ainda que não inteiramente.

Nesse sentido, a tragédia e o barroco afirmam algo a respeito do feminino, não enquanto uma característica das mulheres concretas, mas enquanto uma posição no campo do gozo, que pode ser acessada tanto por mulheres quanto por homens, desde que estejam abertos para acolher a incompletude da linguagem enquanto meio de acesso ao real, uma vez que será impossível abarcá-lo integralmente com as palavras. Nesse sentido, o feminino é não-todo fálico, pois coloca em evidência a "limitação do universo fálico da representação, no qual o sentido nunca é suficiente para dar conta da vida" (MAURANO, 2006, p. 51). Dessa forma, o que se sublinha é que há "uma parte que não está submetida ao sexual e que, por isso, faz apelo a outra coisa: ao ilimitado, ao inacessível, ao invisível” (MAURANO, 2006, p. 51). Esse feminino guarda uma relação com a mística, pois "o Outro, a alteridade que é traumática, não se encontra aí recalcado, mas acolhido em seu mistério" (MAURANO, 2006, p. 51). 


\section{A mística e sua aliança com o infinito e o ilimitado}

Quando Lacan se refere à mística, afirma que ela é "algo de sério, sobre o qual nos informam algumas pessoas, e mais frequentemente mulheres, ou bem gente dotada como São João da Cruz" (LACAN, 2008b [1972-73], p. 81). Trata-se de pessoas que "experimentam a ideia de que deve haver um gozo que esteja mais além", o que o leva a concluir: "É isto que chamamos os místicos" (LACAN, 2008b [1972-73], p. 82).

Seguindo a trilha lacaniana, em uma conferência publicada sob o título O que é uma mulher?, a psicanalista Marie-Hélène Brousse aborda diferentes modos de pensar a questão do feminino e das mulheres na psicanálise. Ela chega à questão dos místicos, afirmando que eles entram em "relação com algo da ordem do infinito e da incompletude" (BROUSSE, 2012, p. 32), em contraste com o corte, a separação, a finitude, o limite dos objetos libidinais demarcados pelo trajeto da pulsão.

A autora levanta uma pergunta sobre a relação entre o gozo feminino e o fim de análise. Por um lado, os místicos "não precisam tanto de análise, de fato, não precisam" (BROUSSE, 2012, p. 32). Por outro lado, não é certo que uma análise conduza necessariamente ao gozo feminino, pois o que ela leva é ao "atravessamento das coordenadas edípicas" através do "trabalho com a cadeia significante" (BROUSSE, 2012, p. 35). Essa ultrapassagem traz "efeitos psíquicos muito potentes", na medida em que leva "a um território que não é mais total e inteiramente regulado pela lógica da castração edípica" (BROUSSE, 2012, p. 35). Apesar de serem caminhos diferentes, Brousse advoga que há algo em comum entre a experiência analítica e a mística:

[...] deve haver algum tipo de paralelismo entre aquilo a que chegamos quando operamos esse atravessamento e aquilo que os místicos testemunham em seus textos, mas em relação ao qual eles próprios não chegaram porque não trabalharam a sua fantasia, porque não trabalharam com suas cadeias significantes, etc. (BROUSSE, 2012, p. 35).

Trata-se, ao final de uma análise, da "descoberta de um espaço que não corresponde inteiramente às coordenadas espaciais da fantasia e do Édipo" (BROUSSE, 2012, p. 36). Essa experiência pode favorecer o acesso ao gozo 
feminino, mas não o garante, pois pode produzir outros efeitos, como um sentimento de despersonalização, o riso ou mesmo a depressão. Em suma, "algo que se sustenta no fato de que as coordenadas habituais do sujeito, as coordenadas nas quais ele se movia, que organizavam o seu desejo etc., são colocadas em outra perspectiva que não funciona da mesma forma" (BROUSSE, 2012, p. 36). As elaborações da autora podem ser articuladas com a questão da dimensão trágica da travessia a ser operada na análise (cf. MAURANO, 2001), contemplada na advertência de Lacan de que "em cada um de nós há a via traçada para um herói", sendo "justamente como homem comum que ele a efetiva" (LACAN, 1988 [1959-1960], p. 383).

A esse respeito, Alain Didier-Weill dá um passo além, quando indica que a impossibilidade do campo da linguagem de dar conta de tudo, expressa no matema lacaniano $S(A)$, significante da falta no campo do Outro, tem como contrapartida a aposta massiva na relação com os objetos, a qual, por orientação do princípio de prazer, tem a função de tamponar essa falta. Mas a análise se coloca para o sujeito como uma aventura curiosa, na medida em que ele cessa de ser determinado pelo limite significante, ao avançar para além do determinismo e "fazer a experiência do encontro disto que, nele, é indeterminado, na medida em que excede todos os limites" (DIDIER-WEILL, 2001, p. 13).

O testemunho do coro das Bacantes, tal como este comparece na tragédia de Eurípedes (1993), referido à origem da tragédia, revela que essas mulheres, ao escutarem não apenas o som da flauta de Dioniso, mas, sobretudo, o que esse som tem de inaudível, de remetimento ao ilimitado, o que era impossível aos homens, partem para a floresta, esquecendo-se de suas identidades de mães e esposas. Para Didier-Weill, o que dever ser destacado nisso é que a substituição da tradição matrilinear pré-helênica pela tradição patrilinear helênica teria produzido um recalque do feminino. As identidades conferidas pela lei da cidade, que satisfazem ao cidadão, não respondem à sua capacidade de escuta do ilimitado nas mulheres. A lei não diz o que é uma mulher, mas, segundo Didier-Weill, "ao contrário, se há alguma coisa que fala dela não é o logos, mas a música de Dioniso" (DIDIER-WEILL, 2001, p. 14).

$\mathrm{O}$ autor salienta que será justamente essa antinomia entre logos e música, entre desejo de limite simbólico e desejo de ilimitado, entre gozo fálico 
e gozo Outro, que o ato trágico terá por função enlaçar. Assim, o ator trágico encarna a divisão do sujeito entre o peso da lei e a leveza da música, sendo disso que advém a falta trágica na Grécia clássica: introduzir no Olimpo, marcado pela lei patrilinear, a música de Dioniso, que transmite os valores matrilineares da antiga religião ctoniana. É dessa maneira que a arte trágica contesta a radicalidade da lei do Nome-do-Pai, exigindo não a sua abolição, mas o seu ultrapassamento.

O ator trágico, ao se destacar do coro, articula a antinomia entre a lei simbólica da cidade e o real ilimitado da música, presentificando a existência sempre faltosa de um sujeito. Seu mérito está em sustentar, ao mesmo tempo, tanto o trabalho de nomeação quanto a existência do inominável. Nesta perspectiva, o "misticismo trágico" 4 (DIDIER-WEILL, 2001, p. 17) que entusiasmou Antígona e que, segundo Didier-Weill, interessa também ao analista, reconhece a existência da lei do pai, mas vai além dele. Aliás, isto só se torna possível porque Antígona "a conhece bastante bem, ao ponto de aí encontrar a falha a partir de onde ela pode transgredi-la" (DIDIER-WEILL, 2001, p. 17). Com o seu ultrapassamento, ela torna imperativo que o caráter inaudível e ilimitado "possa ter direito de cidadania" (DIDIER-WEILL, 2001, p. 17).

Dessa forma, um modo primário de funcionamento, regido pelo princípio de prazer, o qual, na constituição do psiquismo, adota a medida de introjetar o bom e expulsar o mau, que se torna a matriz do horror à diferença, conquista um avanço nos modos de encaminhamento do sujeito trágico, reintroduzindo um efeito na ordem simbólica da lei. Esta, então, terá que acolher "a exigência dessa parte de real oceânico" que o fio das palavras não pode dar conta" (DIDIER-WEILL, 2001, p. 18).

Podemos detectar, portanto, uma afinidade estrutural entre o ato trágico e o ato analítico, que orienta um modo de intervenção e um modo de satisfação que alcança o que se encontra mais além do princípio de prazer. Não é sem razão que recordamos o título de um texto de Freud (1996 [1920]), no qual ele introduz o conceito de pulsão de morte, que é dedicado a um

\footnotetext{
${ }^{4}$ Podemos observar que Didier-Weill não se ocupa da distinção entre mística e misticismo.

${ }^{5} \mathrm{Cf}$. o diálogo entre Freud e Romain Rolland sobre o "sentimento oceânico", especialmente a resposta do criador da psicanálise na primeira parte de 0 mal-estar na cultura (FREUD, 2020 [1930], p. 305-317) e o estudo aprofundado de Vermorel (2018).
} 
profundo questionamento sobre a complexidade dos modos de satisfação que operam no psiquismo. Essa foi a via pela qual Lacan desenvolveu o conceito de gozo, indicando, paradoxalmente, que há um limite àquilo que pode ser dito.

Existem muitos modos de operar com esse limite. Tanto em uma perspectiva devastadora, quanto em uma perspectiva exultante ${ }^{6}$. Neste artigo, nos concentramos em sua dimensão exultante, na qual o "misticismo trágico" remete a um modo de fruição que, ultrapassando os limites do objeto, encontra o "real oceânico" aludido por Didier-Weill, que bem pode ser referido ao gozo Outro, proposto por Lacan.

\section{Considerações finais}

Do ponto de vista psicanalítico, a diferença sexual comparece para o sujeito enquanto enigma, que testemunha uma apreensão simbólica do mundo exterior. A teoria psicanalítica atesta que a cultura se organiza em torno do campo fálico. Contudo, Lacan sinaliza uma orientação ética que se dirige para aquilo que se encontra mais além desse registro, referente a uma dimensão do feminino como aquela que se encontra fora da divisão sexual [hors-sexe] e que se articula com o ilimitado, o infinito e o imaterial. Este norteamento encontra profundas assonâncias com a tragédia e o barroco, os quais desvelam ressonâncias do feminino enquanto aquilo que ultrapassa o fio das palavras.

Portanto, a psicanálise de orientação lacaniana concebe o feminino não apenas enquanto uma posição na partilha dos sexos, mas também enquanto um lugar mais além da divisão sexual. Essa dimensão indica um gozo Outro, que não o fálico, atrelada também ao avanço do tratamento analítico e, em última instância, ao fim de análise. Esse processo articula uma dimensão de perda de seguranças fálicas a uma certa experiência de dessubjetivação, que pode se vincular à conquista de uma ampliação dos horizontes subjetivos e possibilitar um alargamento do enquadramento delimitado pela fantasia (cf. MAURANO, 2006, p. 51-53).

\footnotetext{
${ }^{6}$ Cf. a diferença entre o êxtase (gozo Outro) e o surto (gozo do Outro) no artigo citado anteriormente (MAURANO; ALBUQUERQUE, 2019).
} 
Trata-se, portanto, de partir em direção a um espaço mais além do Édipo, tendo sido capaz de servir-se dele. Essa travessia da fantasia possibilita vislumbrar, ainda que por um instante, a dimensão do real, que se encontra mais além das articulações simbólico-imaginárias. Nesse sentido, o feminino e a mística testemunham os efeitos de um desprendimento das ancoragens narcísicas, em torno das quais a libido tende a se agarrar definitivamente. Ambos consistem em vias que terminam por desmantelar, per via di levare, o excesso de solidez de um eu transformado em mármore, fazendo emergir espaços de fluidez no encontro com o indizível. Então, o sujeito se depara com a própria responsabilidade ética em sua condição de ser falante, a qual pode funcionar como um convite a não desperdiçar a oportunidade de, ao fazer uso da palavra, deixar ressoar, através dela, o testemunho de haver bordejado o silêncio.

\section{Referências}

ARISTÓTELES [349 a.C.]. Ética a Nicômaco. 4. ed. São Paulo: Edipro, 2018.

BROUSSE, M.-H. O que é uma mulher. Latusa digital, ano 9, n. 49, jun. 2012. Disponível em: http://www.latusa.com.br/pdf_latusa_digital_49_a1.pdf. Acesso em: 25 abr. 2016.

DIDIER-WEILL, A. S( A), prefácio. In: MAURANO, D. A face oculta do amor: a tragédia à luz da psicanálise. Rio de Janeiro: Imago, 2001. p. 13-18.

EURÍPIDES. Ifigênia em Áulis; As fenícias; As bacantes. Rio de Janeiro: Zahar, 1993.

FREUD, S. O método psicanalítico freudiano. In: FREUD, S. Fundamentos da clínica psicanalítica. Belo Horizonte: Autêntica, 2017a. p. 51-79. (Obras incompletas de Sigmund Freud).

FREUD, S. As pulsões e seus destinos [1915]. Belo Horizonte: Autêntica, 2017b. (Obras incompletas de Sigmund Freud).

FREUD, S. Além do princípio de prazer [1920]. Rio de Janeiro: Imago, 1996. p. 11-75. (Edição Standard Brasileira, v. XVIII).

FREUD, S. A questão da análise leiga. Conversas com uma pessoa imparcial [1926]. In: FREUD, S. Fundamentos da clínica psicanalítica. Belo Horizonte: Autêntica, 2017c. p. 205-313. (Obras incompletas de Sigmund Freud).

FREUD, S. O mal-estar na cultura [1930]. In: FREUD, S. Cultura, sociedade, religião: o mal-estar na cultura e outros ensaios. Belo Horizonte: Autêntica, 2020. p. 305-410. (Obras incompletas de Sigmund Freud). 
HOMERO. Ilíada [século VIII a.C.] Rio de Janeiro: Nova Fronteira, $2015 a$.

HOMERO. Odisseia [século VIII a.C.] Rio de Janeiro: Nova Fronteira, 2015b.

LACAN, J. [1959-1960]. O seminário, livro 7: a ética da psicanálise. Rio de Janeiro: Zahar, 1988.

LACAN, J. [1959-1960]. O seminário, livro 7: a ética da psicanálise. Rio de Janeiro: Zahar, 2008a.

LACAN, J. [1972-1973]. O seminário, livro 20: mais, ainda. Rio de Janeiro: Zahar, 2008b.

MAURANO, D. A face oculta do amor: a tragédia à luz da psicanálise. Rio de Janeiro: Imago, 2001.

MAURANO, D. A transferência: uma viagem rumo ao continente negro. Rio de Janeiro: Zahar, 2006.

MAURANO, D. A presença do feminino na estética da psicanálise. Revista da Associação Psicanalítica de Curitiba, v. 11, n. 14, p. 29-40, jun. 2007.

MAURANO, D. A perspectiva "musicante" da voz na psicanálise ou notas sobre o ditirambo psicanalítico. In: DIAS, M. M. (Org.). A voz na experiência psicanalítica. São Paulo: Zagodoni, 2015. p. 87-106.

MAURANO, D.; ALBUQUERQUE, B. Lacan e a experiência mística à luz da psicanálise. Revista Latinoamericana de Psicopatologia Fundamental, São Paulo, v. 22, n. 3, p. 439456, set. 2019.

NIETZSCHE, F. O nascimento da tragédia no espírito da música (excertos) [1871]. In: Friedrich Nietzsche: obras incompletas. São Paulo: Nova Cultural, 2000. (Coleção Os pensadores).

SÓFOCLES. A trilogia tebana: Édipo Rei, Édipo em Colono, Antígona. Trad. Mario da Gama Kury. Rio de Janeiro: Zahar, 1990.

VERMOREL, H. Sigmund Freud et Romain Rolland: un dialogue (1923-1936). Paris: Albin Michel, 2018.

VORSATZ, I. Antígona e a ética trágica da psicanálise. Rio de Janeiro: Zahar/FAPERJ, 2013. 